\title{
Differential cardiovascular profiles of sodium- glucose cotransporter 2 inhibitors: critical evaluation of empagliflozin
}

This article was published in the following Dove Press journal:

Therapeutics and Clinical Risk Management

3 May 2017

Number of times this article has been viewed

\author{
Vani P Sanon' \\ Shalin Patel' \\ Saurabh Sanon ${ }^{2}$ \\ Ruben Rodriguez \\ Son V Pham' \\ Robert Chilton' \\ 'Division of Cardiology, University of \\ Texas Health Science Center at San \\ Antonio, Audie L Murphy VA Hospital, \\ San Antonio, TX, ${ }^{2}$ Interventional \\ Cardiology-Structural Heart \\ Disease, Cardiology Consultants at \\ Baptist Heart and Vascular Institute, \\ Pensacola, FL, USA
}

\begin{abstract}
One of the most feared repercussions of type 2 diabetes mellitus is the risk of adverse cardiovascular outcomes. The current antidiabetic agents on the market have had difficulty in showing cardiovascular outcome improvement. The EMPA-REG OUTCOME trial studied the sodium-glucose cotransporter 2 inhibitor empagliflozin in type 2 diabetic patients at high risk of cardiovascular events. The trial results revealed a decrease in the composite primary end points of death from cardiovascular causes, nonfatal myocardial infarction, and nonfatal stroke in those taking empagliflozin vs placebo. Those taking the medication also had a significant decrease in death from any cause, death from cardiovascular cause, and hospitalization for heart failure. The EMPA-REG trial is paradigm shifting because it demonstrates a clear mortality benefit to cardiovascular outcomes with a low side-effect profile, in contrast to prior outcome studies of hypoglycemic agents. Further studies are required to better clarify the long-term safety and efficacy of this promising class of diabetic drugs.
\end{abstract}

Keywords: SGLT2 inhibitors, diabetes, cardiovascular mortality, heart failure, hypertension

\section{Introduction}

Increased risk of cardiovascular outcomes is a known complication of diabetes mellitus. The current literature on cardiovascular event rates in type 2 diabetic patients is summarized as follows. The "Look AHEAD" trial enrolled 5,145 overweight or obese patients with type 2 diabetes to an intensive lifestyle intervention and had a primary composite outcome of death from cardiovascular causes, nonfatal myocardial infarction (MI), nonfatal stroke, or hospitalization for angina during a maximum follow-up of 13.5 years (median follow-up 9.6 years). ${ }^{1}$ The trial concluded that an intensive lifestyle intervention focusing on weight loss did not reduce the rate of cardiovascular events in overweight or obese adults with type 2 diabetes. Moreover, the trial highlighted the contemporary cardiovascular (CV) event rates in patients with type 2 diabetes. The macrovascular event rate in type 2 diabetic patients was found to be on par with being a cardiovascular disease risk equivalent $(\sim 20 \%$ at 10 years). Many large randomized control trials (RCTs), such as the UKPDS study, have demonstrated a significant reduction in microvascular events in patients treated with hypoglycemic agents leading to a reduced hemoglobin A1c. ${ }^{2}$ However, on review of the current large safety trials using hypoglycemic agents, the impact on $\mathrm{CV}$ event rate has been rare.

Cardiovascular outcome trials for antiglycemic medications have been abundant in recent years. This may be in part due to an US FDA mandate released in 2008 which stated that cardiovascular safety could be assessed in new antidiabetic
Correspondence: Robert Chilton Division of Cardiology, University of Texas Health Science Center, 7703 Floyd Curl Dr, San Antonio, TX 78229, USA Email chiltonr@gmail.com 
therapies before and after FDA approval. ${ }^{3,4}$ This was largely a reaction to the PROACTIVE trial, which was a large RCT that evaluated cardiovascular outcomes in the PPAR $\gamma$ agonist pioglitazone vs placebo in high-risk individuals. ${ }^{5}$ The results demonstrate a statistically significant increase in heart failure events, which largely overshadowed the positive findings that showed significant decrease in the "main" secondary outcome composite of death from any cause, MI (excluding silent MI), and CVA accident in the treatment group. Prior to PROACTIVE trial, metformin was shown to have cardiovascular benefits in patients with newly diagnosed type 2 diabetes in the UKPDS trial; however, this benefit was only shown in a small subgroup of overweight individuals and, in fact, increased mortality was noted in those concurrently taking sulfonylurea. ${ }^{6}$ Table 1 summarizes the selected large RCTs on oral hypoglycemic agents and their impact on CV outcomes, including the EMPA-REG study.

In contrast, the sodium-glucose cotransporter 2 (SGLT2) inhibitors are a novel group of diabetes medications that offer a revolutionary significant reduction in hospitalization for heart failure and cardiovascular morbidity and mortality (Figure 1). In this review, we highlight the mechanism of action and cardiovascular benefits of SGLT2 inhibitors, particularly empagliflozin.

\section{SGLT2 inhibitors}

SGLTs are a group of proteins that facilitate glucose diffusion across the cell membrane and participate in glucose homeostasis. SGLT1 and SGLT2 are carrier membrane

Table I Relevant major CV outcome studies with oral hypoglycemics

\begin{tabular}{|c|c|c|c|}
\hline Trial & Details & Results & Comments \\
\hline UKPDS $^{6}$ & $\begin{array}{l}\text { - N=4,075 patients with DM } \\
\text { - Primary end point } \\
\circ \text { Death } \\
\circ \text { All-cause mortality } \\
\text { - DM-related end point } \\
\text { - Secondary end point } \\
\circ \text { MI, CVA, PVD, microvascular events } \\
\text { - Nonoverweight patients randomized to } \\
\text { either intensive therapy with sulfonylurea, } \\
\text { insulin, or diet } \\
\text { - Subset of } 342 \text { overweight patients } \\
\text { randomized to metformin, intensive therapy } \\
\text { with a sulfonylurea, or insulin. }\end{array}$ & $\begin{array}{l}\text { - Improvement in microvascular events but } \\
\text { no improvement in macrovascular events in } \\
\text { nonoverweight patients } \\
\text { - In the overweight subgroup, metformin } \\
\text { - Reduced all-cause mortality } 36 \% \\
(9-55, P=0.01 \mathrm{I}) \\
\text { Reduced diabetes-related death } 42 \% \\
(9-63, P=0.017) \\
\text { Risk reductions of } 32 \% \text { ( } 95 \% \mathrm{Cl}: 13-47 \text {, } \\
P=0.002) \text { for any diabetes-related end } \\
\text { point. }\end{array}$ & $\begin{array}{l}\text { - Increased mortality in a } \\
\text { subgroup of patients given } \\
\text { metformin and sulfonylurea. }\end{array}$ \\
\hline PROACTIVE $^{5}$ & $\begin{array}{l}\text { - } \mathrm{N}=5,238 \text { patients with type } 2 \mathrm{DM} \text { and } \\
\text { macrovascular disease (MI or CVA within } \\
6 \mathrm{mo}, \mathrm{PCl} \text { or CABG within } 6 \text { mo or } \\
\text { objective evidence of CAD or PVD). } \\
\text { - Randomized to pioglitazone or placebo } \\
\text { - Primary end point } \\
\text { - All-cause mortality, nonfatal MI, CVA, } \\
\text { ACS, vascular intervention, or amputation } \\
\text { - Secondary end points } \\
\text { - Death from any cause, MI (excluding } \\
\text { silent MI), and CVA. }\end{array}$ & $\begin{array}{l}\text { - Significant decrease in the secondary } \\
\text { outcome in pioglitazone vs placebo } 30 \text { I vs } \\
358 ; \mathrm{HR} 0.84 ; \mathrm{Cl}: 0.72-0.98 ; P=0.027 \text {. }\end{array}$ & $\begin{array}{l}\text { - Statistically significant } \\
\text { increase in heart failure } \\
\text { events ( } 4 \text { I } 7 \text { vs } 302 \text {; } \\
P<0.000 \text { I) in the treatment } \\
\text { group. }\end{array}$ \\
\hline $\begin{array}{l}\text { EMPA-REG } \\
\text { OUTCOME }^{18}\end{array}$ & $\begin{array}{l}\text { - N=7,020 patients with cardiovascular } \\
\text { disease to either empagliflozin or placebo } \\
\text { - Primary outcome } \\
\text { - Death from cardiovascular causes, } \\
\text { nonfatal MI, (excluding silent MI), } \\
\text { or nonfatal stroke. } \\
\text { - Secondary outcome } \\
\text { - Composite of the primary outcome plus } \\
\text { hospitalization for unstable angina. }\end{array}$ & $\begin{array}{l}\text { Reduction in primary composite outcome } \\
\text { at } 10.5 \% \text { vs I } 2.1 \%, \mathrm{HR} 0.86 \text {, } \\
\mathrm{Cl}: 0.74-0.99, \mathrm{P}=0.04 \\
\text { - Reduction in CV death } 3.7 \% \text { vs } 5.9 \% \text {, } \\
\text { HR } 0.62, \mathrm{Cl}: 0.49-0.77, P<0.00 \mathrm{I} \\
\text { - Reduced all-cause mortality } 5.7 \% \text { vs } 8.3 \% \text {, } \\
\text { HR } 0.68, \mathrm{Cl}: 0.57-0.82, P<0.00 \mathrm{I} \\
\text { - Reduced hospitalizations for heart failure } \\
2.7 \% \text { vs } 4.1 \%, \mathrm{HR} 0.65, \mathrm{Cl}: 0.50-0.85 \\
\text { - Reduction in weight, waist circumference, } \\
\text { and systolic blood pressure. }\end{array}$ & $\begin{array}{l}\text { - Increased genital infections } \\
(6.4 \% \text { vs I.8\%; } P<0.00 \mathrm{I}) \text {. }\end{array}$ \\
\hline
\end{tabular}

Abbreviations: ACS, acute coronary syndrome; CV, cardiovascular; DM, diabetes mellitus; MI, myocardial infarction; CVA, cardiovascular accident; mo, months; CAD, coronary artery disease; $\mathrm{HR}$, hazard ratio; $\mathrm{Cl}$, confidence interval; PVD, peripheral vascular disease; $\mathrm{PCl}$, percutaneous coronary intervention; CABG, coronary artery bypass graph. 


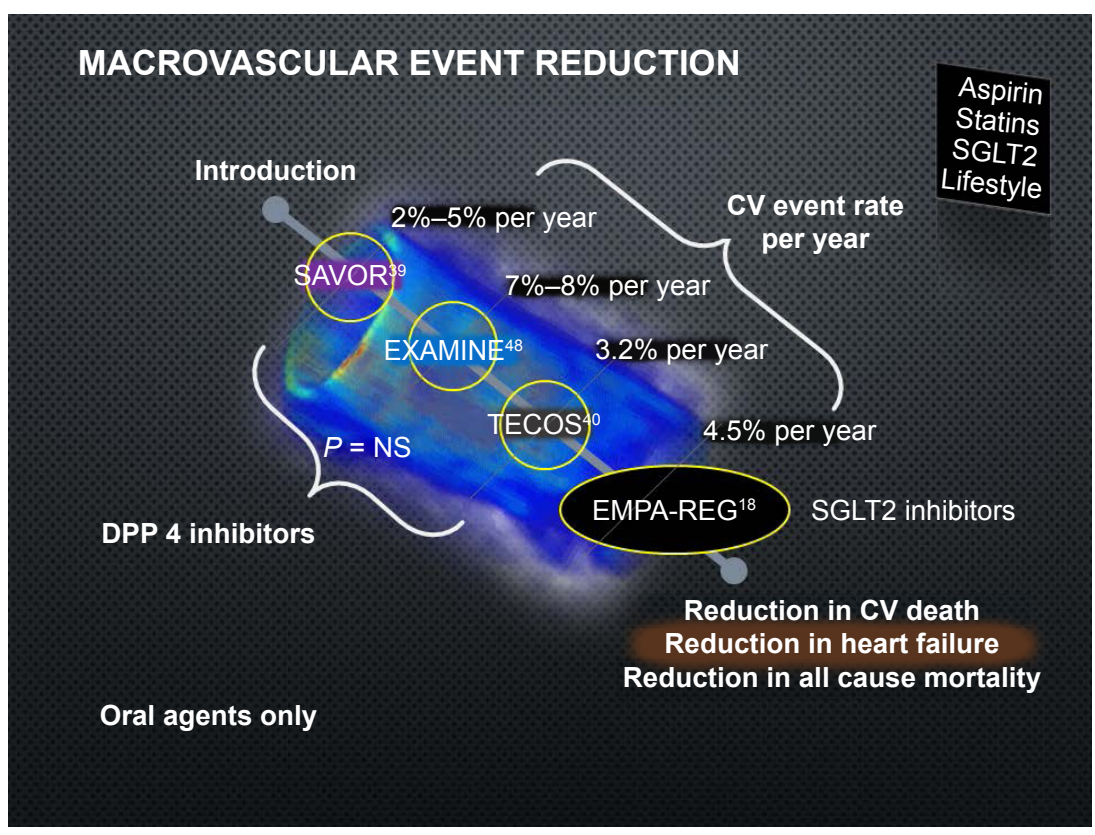

Figure I The recent hypoglycemia trials for diabetes with cardiovascular event rates per year.

Note: Note the marked reduction in CV death, hospitalizations for heart failure, and all-cause mortality with empagliflozin.

Abbreviations: CV, cardiovascular; SGLT2, sodium-glucose cotransporter 2; NS, nonsignificant; SAVOR, saxagliptin reduce the risk of cardiovascular events; EXAMINE, examination of cardiovascular outcomes with alogliptin versus standard of care; TECOS, trial evaluating cardiovascular outcomes with sitagliptin; EMPA-REG, empagliflozin, cardiovascular outcomes, and mortality in type 2 diabetes.

transporters that couple glucose transport against its concentration gradient into renal tubular epithelial cell with sodium influx across cell membrane down its electrochemical gradient. SGLT2 carrier proteins are predominantly concentrated in the kidney, especially on the epithelial cells of luminal membranes of $\mathrm{S} 1 / \mathrm{S} 2$ segment in the proximal convoluted tubule. ${ }^{7}$ Under normal circumstances, SGLT2 is a low glucose affinity, high-capacity carrier protein that is highly selective for glucose and has a more potent role in renal glucose reabsorption compared to SGLT1. SGLT2mediated glucose transport is responsible for reabsorption of $\sim 97 \%$ of glomerular filtrate. ${ }^{8}$ Studies in human and animal models demonstrate that there is substantial upregulation of SGLT2 mRNA and protein expression in epithelial cells of the proximal tubule in chronically hyperglycemic states. ${ }^{9,10}$ This maladaptive response to hyperglycemia causes greater renal reabsorption of glucose and has important implications in patients with diabetes. As a result, SLGT2 inhibition is a vital therapeutic target in diabetes and has led to the approval of several novel SGLT2 inhibitors, which are named gliflozins.

To date, three SGLT2 inhibitors have been FDA approved in US: canagliflozin, dapagliflozin, and empagliflozin. Similarly, ipragliflozin, tofogliflozin, and luseofliglozin are approved in Japan with several other agents in development. SLGT2 inhibitors as a class effect reduce plasma glucose concentration by enhancing glycosuria and reduce fractional glucose reabsorption to $40 \%-50 \% .^{11-13}$ This mechanism is independent of insulin action or beta-cell function and is unique in the current armamentarium of hypoglycemic agents available in the management of diabetes. Generally, these SGLT2 inhibitors generate urinary glucose loss of 40-80 g/day and average reduction in $\mathrm{HbA} 1 \mathrm{c}$ of $0.7 \%-0.9 \%$. Chronic SGLT2 inhibition leads to cumulative negative energy balance and causes an average weight loss of 2-3 kg. ${ }^{14,15}$

Also, SGLT2 inhibition augments osmotic diuresis by increasing filtered glucose load and impairing sodium reabsorption in proximal tubule. This diuretic effect contributes to the weight loss by a modest reduction in extracellular volume and reduction in systolic BP by $3-5 \mathrm{mmHg}$. Data from animal models suggest that SGLT2 inhibition can also mitigate the renin-angiotensin-aldosterone response to hyperglycemia, which is implicated in hypertension associated with diabetes (Figure 2). ${ }^{16}$ Another effect of SGLT2 inhibition is to reduce insulin resistance by alleviating glucotoxicity, which has been demonstrated with a minimum of 2 weeks of dapagliflozin treatment. $^{17}$

In totality, the effects of the negative energy balance, weight loss, reduction in blood pressure (BP), and edema are observed as a class effect through chronic SGLT2 inhibition. This is paradigm altering in the management of diabetes and 


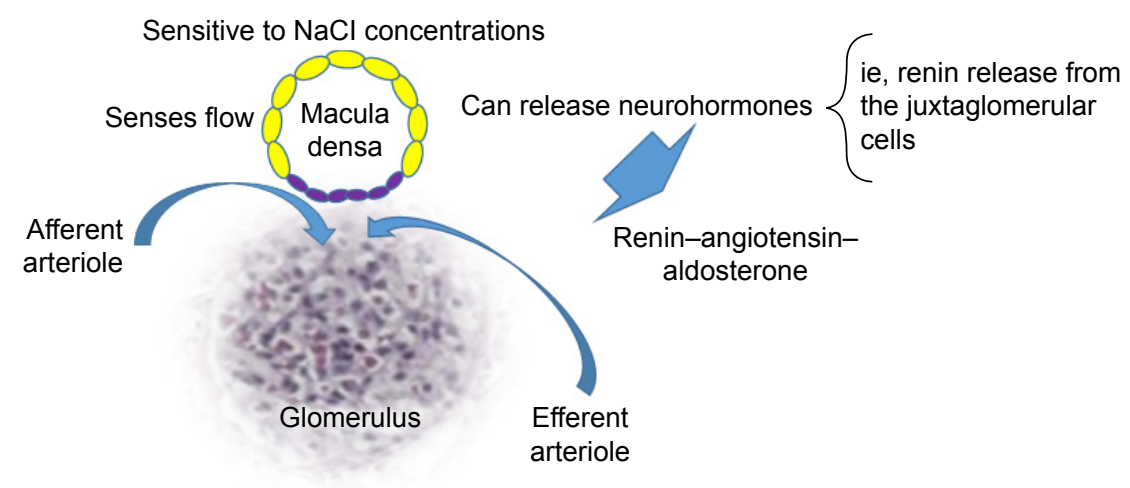

Figure 2 The macula densa and SGLT2 inhibitors.

Notes: The effect of marked diuresis and flow changes could have major impact on activation of macular densa cells. Recent reports have noted significant changes in aldosterone levels. Clinical importance remains to be determined.

Abbreviation: SGLT2, sodium-glucose cotransporter 2.

hypertension associated with diabetes. Currently, several large randomized CV outcome studies involving SGLT2 inhibitors are underway and will shed light on whether these favorable surrogate outcomes translate into reduction in long-term clinical event rates. The EMPA-REG OUTCOME study answers some of those questions.

\section{The EMPA-REG trial}

The EMPA-REG trial was a randomized controlled, doubleblinded trial on the cardiovascular safety of the SGLT2 inhibitor empagliflozin in a cohort of patients with type 2 diabetes at high cardiovascular risk. ${ }^{18}$ The trial also highlighted the potential of empagliflozin to confer benefits on micro- and macrovascular outcomes. Enrolled patients were found to have at least one of the following: history of MI, evidence of multivessel coronary artery disease (CAD), single-vessel CAD with either positive stress test or recently hospitalized for unstable angina, unstable angina with $\mathrm{CAD}$, history of stroke, or peripheral artery disease. The trial enrolled 7,020 patients with cardiovascular disease at 590 different sites in 42 countries; patients were randomized to empagliflozin $10 \mathrm{mg}, 25 \mathrm{mg}$, or placebo with a median follow-up of 3.1 years. The primary composite outcome was death from cardiovascular causes, nonfatal MI, or nonfatal stroke, as analyzed in the pooled empagliflozin group vs the placebo group. The secondary composite outcome was the primary outcome plus hospitalization for unstable angina. The primary outcome occurred in $10.5 \%$ of patients in the empagliflozin group vs $12.1 \%$ of patients in the placebo group (hazard ratio [HR] 0.86, confidence interval $[\mathrm{CI}]: 0.74-0.99, P=0.04)$. The secondary outcome showed noninferiority in empagliflozin group. The patients taking empagliflozin also had significantly less risk of death from cardiovascular causes $(3.7 \%$ vs $5.9 \%$, HR 0.62 , CI: $0.49-0.77, P<0.001)$, death from any cause $(5.7 \%$ vs $8.3 \%$, HR 0.68, CI: $0.57-0.82, P<0.001)$, and hospitalization for heart failure (2.7\% vs $4.1 \%$, HR 0.65 , CI: $0.50-0.85)$. Interestingly, empagliflozin showed a significant benefit in cardiovascular risk factor reduction, including a reduction in weight, waist circumference, and systolic BP. In summary, empagliflozin compared to placebo reduced the risk of allcause death (number needed to treat $[\mathrm{NNT}]=38 / 3$ years) and composite cardiovascular events ( $\mathrm{NNT}=63 / 3$ years); Figure 3 illustrates the aforementioned $\mathrm{CV}$ benefit of empagliflozin as compared to commonly used cardiac drugs such as simvastatin and ramipril.

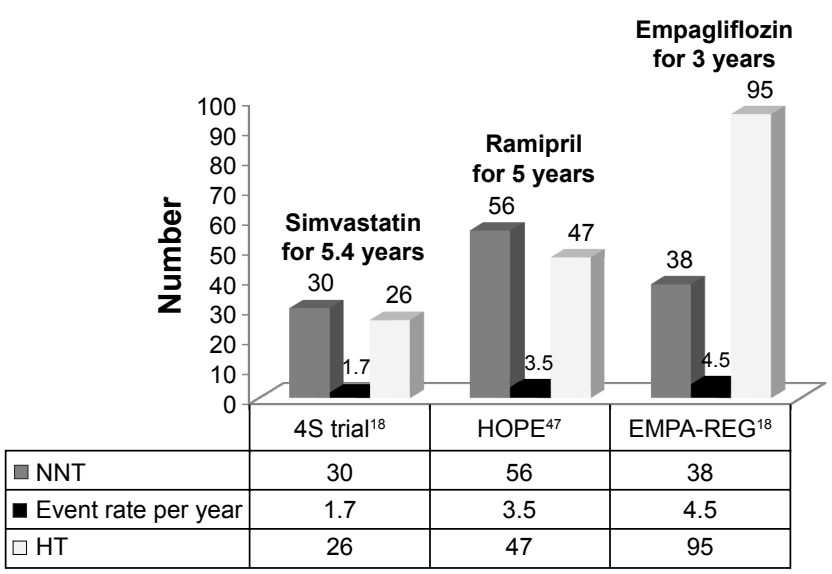

Figure 3 Three large CV outcome trials have increasing cardiovascular event rates as diabetes is added to high-risk patients.

Notes: There is increase in the percentage of patients with hypertension in the more recent diabetes trials. $4 \mathrm{~S}$ trial simvastatin: I82/2,22 I (8.2\%), placebo: $256 / 2,223$ (II.5\%) HR =0.7I (0.59-0.85), HOPE trial ramipril: 482/4,645 (10.4\%), placebo: $569 / 4,652$ (12.2\%) HR =0.85 (0.76-0.95), EMPA-REG empa: 269 (5.7\%)/2,333, placebo: $194(8.3 \%) / 4,687 \mathrm{HR}=0.68(0.57-0.82)$. The number needed to treat calculations find that empagliflozin in only 3 years has a NNT that is very close to $4 \mathrm{~S}$ that needed 5.4 years to have NNT of 30 .

Abbreviations: $\mathrm{CV}$, cardiovascular; HR, hazard ratio; NNT, number needed to treat; $\mathrm{HT}$, hypertension. 


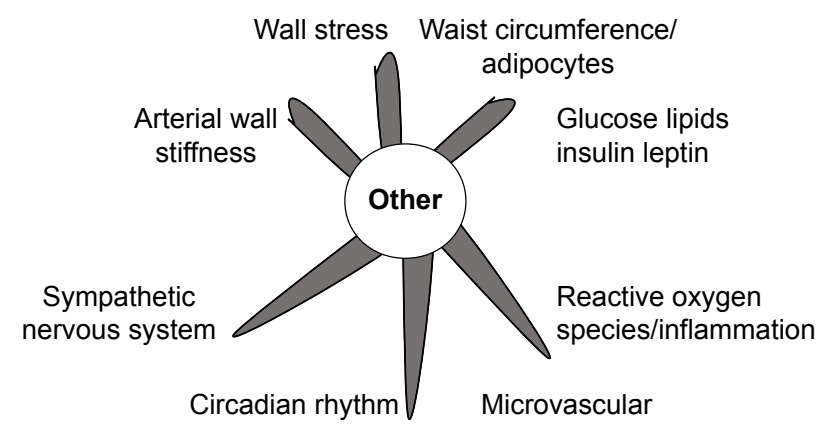

Figure 4 Potential mechanism reducing cardiovascular events.

The only significant side effect was an increase in genital infections $(6.4 \%$ vs $1.8 \% ; P<0.001)$. The increased risk of genital infections was noted in both males (number needed to harm $[\mathrm{NNH}]=29 / 3$ years $)$ and females $(\mathrm{NNH}=14 / 3$ years $)$. Moreover, the incidence of urosepsis was also increased with empagliflozin $(0.4 \%$ vs $0.1 \%)$.

\section{Cardiovascular benefits and possible mechanisms related to reduced CV events with empagliflozin}

SGLT2 inhibitors have been shown so far to reduce BP, aortic stiffness, calories, body weight, and blood glucose and to increase osmotic diuresis (Figure 4).

The clinical importance of nine modifiable risk factors account for $>90 \%$ of the risk of first MI from the INTERHEART case-controlled study that enrolled 15,152 cases and 14,820 age- and sex-matched controls worldwide. Diabetes was in one of the top three risk factors for $\mathrm{CV}$ disease and acute MI. ${ }^{19}$ The two other major modifiable risk factors improved by SGLT2 inhibitors are hypertension and abdominal obesity.

SGLT2 inhibitors are known to reduce BP. ${ }^{20}$ The range of systolic BP reduction varied from $3.7 \mathrm{mmHg}$ to $7.5 \mathrm{mmHg}$ over four trials. Some trials have found a small improvement in BP reduction as the dose of SGLT2 inhibitors is increased. In regard to empagliflozin, a recent meta-analysis of ten RCTs showed that a dose of $25 \mathrm{mg}$ caused a reduction in systolic BP weighted mean difference (WMD) of $-4.19 \mathrm{mmHg}$ (CI: $-5.17 \mathrm{mmHg}$ to $-3.20 \mathrm{mmHg}$; $\mathrm{I}=32 \%$ ) and diastolic BP WMD of $-1.88 \mathrm{mmHg}$ (CI: $-2.71 \mathrm{mmHg}$ to $-1.04 \mathrm{mmHg}$; $\mathrm{I} 2=56 \%$ ) compared to placebo. ${ }^{21}$ These changes were similar to those found in EMPA-REG OUTCOME trial. The reduction in BP has many known cardiovascular benefits. At a basic level, myocyte contraction is the primary factor determining myocardial oxygen consumption $\left(\mathrm{MVO}_{2}\right)$. The main clinical components of $\mathrm{MVO}_{2}$ are primarily $\mathrm{BP}$ (wall tension), contractility, and heart rate. ${ }^{6}$ In addition, the highrisk vulnerable plaque morphology (increased lipid/necrotic core/thin fibrous cap/vascular inflammation) coupled with increased wall stress from sudden and sustained BP elevations leads to increased risk for plaque rupture (Figure 5). Reduction in BP would reduce a well-known risk factor for acute $\mathrm{CV}$ events. ${ }^{22}$ Figure 6 illustrates mortality benefit associated with BP reduction.
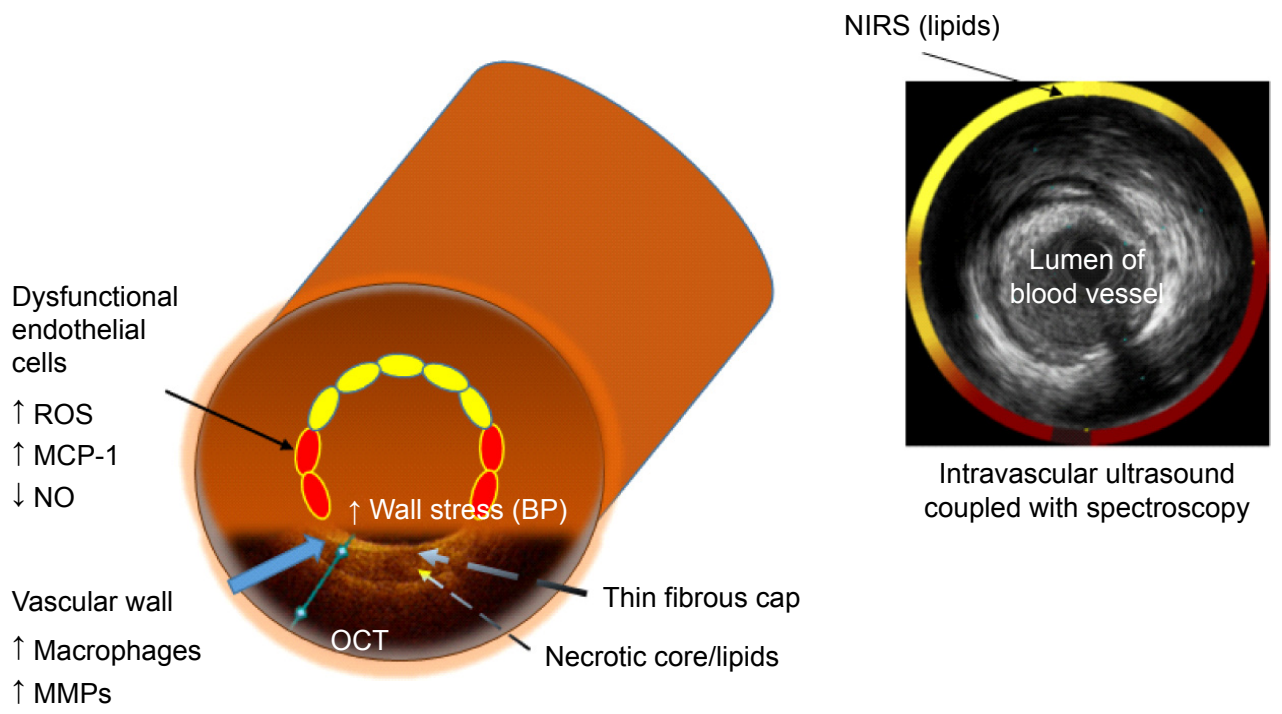

Figure $\mathbf{5}$ The vascular wall in patients with diabetes is well known to have advanced atherosclerosis.

Notes: The wall stress increases stress on the diseased diabetes vascular wall leading to plaque fracture. The thin cap is not as elastic, and the stiffness of this plaque cap increases the risk for plaque rupture. In addition, the cap frequently is much thinner with a necrotic core as seen in the PROSPECT trial. ${ }^{23,49}$

Abbreviations: BP, blood pressure; NIRS, near infrared spectroscopy; ROS, reactive oxygen species; MCP-I, monocyte chemoattractant protein-I; MMP, matrix metalloproteinase; OCT, optical coherence tomography; NO, nitric oxide. 


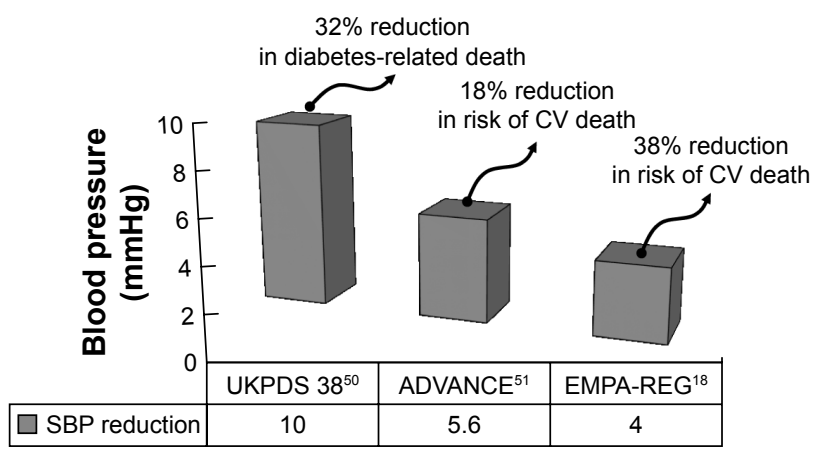

Figure 6 Reductions in systolic blood pressure are well known to reduce CV risk from multiple studies.

Notes: These three large trials found similar benefits with the caveat that EMPAREG has an impressive reduction in CV death. This suggests that SGLT2 inhibitors may have multiple mechanisms related to reducing $\mathrm{CV}$ events in diabetic patients.

Abbreviations: CV, cardiovascular; SGLT2, sodium-glucose cotransporter 2; SBP, systolic blood pressure.

Recent evidence may also indicate that empagliflozin has benefits outside the cardiovascular system. At a basic science level, empagliflozin has been found to reduce monocyte chemoattractant protein-1, intercellular adhesion molecule-1, plasminogen activator inhibitor-1, transforming growth factor- $\beta$, and connective tissue growth factor in the diabetic kidney. ${ }^{23}$ This suggests anti-inflammatory and antifibrotic properties to the diabetic kidney and may suggest that empagliflozin confers renal protection as well. Further translational studies would have to be performed to confirm these findings.

\section{Heart failure and empagliflozin}

Heart failure hospitalizations are a major cause of mortality and morbidity in patients with diabetes. The EMPA-REG trial found early reductions in hospitalization for heart failure in patients treated with empagliflozin (Figure 7). This very early reduction in heart failure hospitalizations may represent the benefit of a reduction in the high left ventricular end-diastolic pressure that is frequently found in hypertensive diabetic patients due to empagliflozin-mediated osmotic diuresis.

Even normotensive patients with type 2 diabetes may be affected by diastolic dysfunction, as suggested in a case-control study $(\mathrm{N}=127)$ of these patients of $>5$ years duration. Greater than $50 \%$ prevalence of asymptomatic left ventricular diastolic dysfunction was reported, despite not being hypertensive. ${ }^{24}$ In addition, recent large RCTs (SAVOR, EXAMINE, and TECOS) with oral hypoglycemic agents have included $>80 \%$ of patients with hypertension. Greater than $90 \%$ of patients in EMPA-REG also had hypertension. Given this information, it would be reasonable to suggest that a large number of patients in the EMPA-REG trial, as well as diabetics in general, have some degree of diastolic dysfunction. The frequent relationship between hypertension and diastolic dysfunction has been

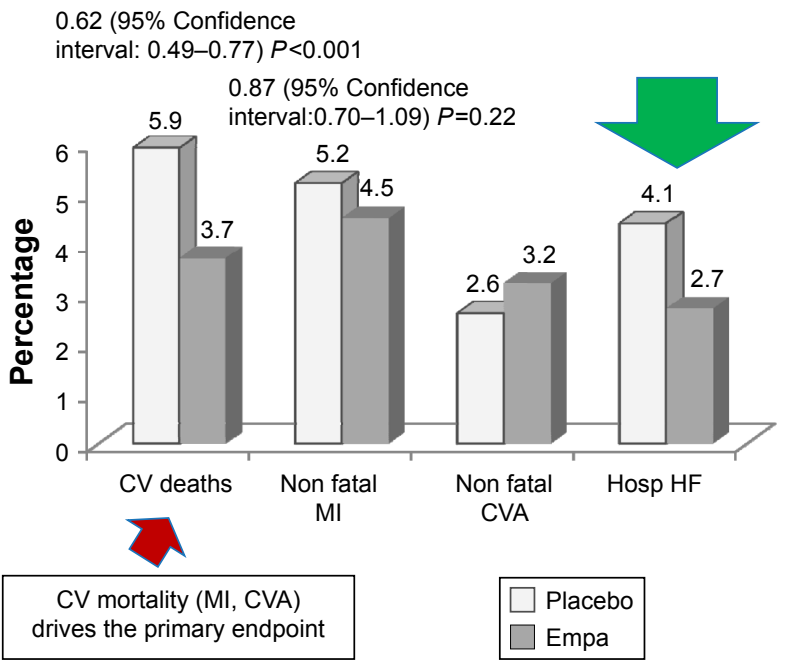

Figure 7 The significant reduction in both CV deaths and hospitalization for heart failure.

Abbreviations: CV, cardiovascular; MI, myocardial infarction; CVA, cardiovascular accident; hosp, hospitalization; HF, heart failure.

well established in a number of recent studies. ${ }^{25,26}$ Based on the current literature on hypertension and diastolic dysfunction, up to $50 \%$ of patients with hypertension have evidence of diastolic dysfunction, which in turn has been linked to a tenfold increased risk of mortality. ${ }^{25}$ Unfortunately, there are no clear treatments for diastolic dysfunction except for symptomatic relief with diuresis and BP control, both of which empagliflozin addresses. It seems that the abnormal ventricular matrix found in the hypertensive patient is best treated with early prevention and global risk reduction.

SGLT2 inhibitors have also shown improvement in pulse pressure and aortic stiffness measured noninvasively. ${ }^{27}$ Widened pulse pressure is a marker for increased vascular stiffness and is associated with adverse cardiovascular outcomes. ${ }^{28}$ Moreover, pulse pressure predicts $\mathrm{CV}$ events independent of standard $\mathrm{CV}$ risk factors. ${ }^{29}$ In addition, as Franklin et $\mathrm{al}^{30}$ have reported in the Framingham Heart Study, the relationship between pulse pressure and coronary disease strengthens with increasing age. It is well known that diastolic dysfunction is associated with abnormal vascular stiffness. In a small study by Molttram and associates, 70 hypertensive patients with exertional dyspnea were evaluated for diastolic dysfunction and arterial compliance. Their findings indicate a significant correlation of progressive abnormal diastolic function with reduced arterial compliance. ${ }^{31}$ Authors concluded that arterial compliance is an independent predictor of diastolic dysfunction in patients with hypertensive heart disease. Improvement in arterial stiffness and diastolic dysfunction may play a key role in both empagliflozin's ability to reduce CV events and hospitalizations from heart failure. 
Table 2 Keypoints and clinical impact of empagliflozin

\section{Outcomes vs placebo:}

Reduction in CV death (3.7\% vs $5.9 \%$, HR 0.62 )

Reduction in all-cause mortality ( $5.7 \%$ vs $8.3 \%$, HR 0.68$)$

Reduction in hospitalization for heart failure ( $2.7 \%$ vs $4.1 \%$, HR 0.65 )

Surrogate effects:

Osmotic diuresis

Lowers blood sugar: $\mathrm{HbAlc}$ reduction of $-0.66 \%$ $\%^{21}$

Lowers blood pressure: WMD reduction of $-4.19 \mathrm{mmHg} /-1.88 \mathrm{mmHg}^{21}$

Lowers weight: $1.84 \mathrm{~kg}$ reduction ${ }^{21}$

Lowers waist circumference: $\sim 2 \mathrm{~cm}$ reduction ${ }^{18}$

Decrease in pulse pressure: $2.3 \mathrm{mmHg}$ reduction ${ }^{27}$

Increases HDL: increases $\sim 2 \mathrm{mg} / \mathrm{dL}^{18}$

Decreases uric acid: decreases $0.4 \mathrm{mg} / \mathrm{dL}^{18}$

Abbreviations: $\mathrm{CV}$, cardiovascular; $\mathrm{HR}$, hazard ratio; HbAlc, hemoglobin AIC; WMD, weighted mean difference; HDL, high-density lipoprotein.

Diabetes is likely independently contributing to the increased arterial stiffness without coexisting hypertension. At the translational biology level, patients with diabetes have increased advanced glycation end products. Hyperglycemia, insulin resistance, and increased glycation end products lead to the development of increased vascular stiffness. At the cellular level, microvascular disease and vascular stiffness are mediated by the interaction of receptors such as lectin-like oxidized low-density lipoprotein receptor-1 and macrophage scavenger receptors to advanced glycation end products. ${ }^{32,33}$

\section{Weight loss and empagliflozin}

In contrast to other antiglycemic agents such as sulfonylureas, which are known to cause weight gain, the SGLT2 inhibitors have been shown to cause weight loss. ${ }^{34} \mathrm{~A}$ recent meta-analysis showed that patients taking empagliflozin lost $-1.84 \mathrm{~kg}$ (CI: -2.30 to -1.38 ) when compared to placebo. ${ }^{21}$ These results were similar to what was seen in the EMPA-REG OUTCOME trial as well as meta-analysis of dapagliflozin. Canagliflozin seemed to show a slightly higher weight reduction with meta-analysis of ten RCTs showing WMD $-2.81 \mathrm{~kg}(\mathrm{CI}$ : -3.26 to -2.37$) .{ }^{35} \mathrm{~A}$ recent trial comparing glimepiride and canagliflozin used X-ray absorptiometry scans to determine the etiology of weight change. It was found that about two-thirds of the weight loss in canagliflozin was attributed to a loss in fat mass, whereas glimepiride caused increased body weight from lean body mass as well as fat. ${ }^{36}$ Given that a majority of the weight loss in SGLT2s is attributed to fat loss, this would correlate with the reduction in waist circumference of $\sim 2 \mathrm{~cm}$ in patients as seen in the EMPA-REG OUTCOME trial. ${ }^{18,21,36-38}$

\section{Conclusion}

SGLT2 inhibitors, particularly empagliflozin are a revolutionary class of drugs for diabetes, which have shown CV event reduction including reduction in $\mathrm{CV}$ death, hospitalizations for heart failure, reduction in BP, aortic stiffness, and weight loss (Table 2). Further research is needed to clarify and validate the $\mathrm{CV}$ benefits of empagliflozin at the translational biology level as well as its impact on clinical medicine.

\section{Acknowledgment}

The authors want to thank Ryan Marsh for his contribution to this paper.

\section{Disclosure}

Dr Robert Chilton serves on advisory boards and research for BI, Lilly, Takada, Pfizer, and MSD. The authors report no further conflicts of interest in this work.

\section{References}

1. Look AHEAD Research Group, Wing RR, Bolin P, et al. Cardiovascular effects of intensive lifestyle intervention in type 2 diabetes. $N$ Engl J Med. 2013;369(2):145-154.

2. King P, Peacock I, Donnelly R. The UK Prospective Diabetes Study (UKPDS): clinical and therapeutic implications for type 2 diabetes. Br J Clin Pharmacol. 1999;48(5):643-648.

3. U.S. Department of Health and Human Services Food and Drug Administration Center for Drug Evaluation and Research (CDER) [webpage on the Internet]. Guidance for Industry Diabetes Mellitus Evaluating Cardiovascular Risk in New Antidiabetic Therapies to Treat Type 2 Diabetes. Available from: http://www.fda.gov/downloads/drugs/ guidancecomplianceregulatoryinformation/guidances/ucm071627.pdf. Accessed February 14, 2016.

4. Hirshberg B, Raz I. Impact of the U.S. food and drug administration cardiovascular assessment requirements on the development of novel antidiabetes drugs. Diabetes Care. 2011;34(suppl 2):S101-S106.

5. Dormandy JA, Charbonnel B, Eckland DJ, et al. Secondary prevention of macrovascular events in patients with type 2 diabetes in the PROactive study (PROspective pioglitAzone clinical trial in macroVascular events): a randomised controlled trial. Lancet. 2005; 366(9493):1279-1289.

6. Effect of intensive blood-glucose control with metformin on complications in overweight patients with type 2 diabetes (UKPDS 34). Lancet. 1998;352(9131):854-865.

7. Wright EM, Hirayama BA, Loo DF. Active sugar transport in health and disease. J Intern Med. 2007;261(1):32-43.

8. Turk E, Martin MG, Wright EM. Structure of the human $\mathrm{Na}+$ / glucose cotransporter gene SGLT1. J Biol Chem. 1994;269(21): 15204-15209.

9. Freitas HS, Anhe GF, Melo KF, et al. $\mathrm{Na}(+)$-glucose transporter-2 messenger ribonucleic acid expression in kidney of diabetic rats correlates with glycemic levels: involvement of hepatocyte nuclear factor-1alpha expression and activity. Endocrinology. 2008;149(2): 717-724.

10. Rahmoune H, Thompson PW, Ward JM, Smith CD, Hong G, Brown J. Glucose transporters in human renal proximal tubular cells isolated from the urine of patients with non-insulin-dependent diabetes. Diabetes. 2005;54(12):3427-3434.

11. Komoroski B, Vachharajani N, Boulton D, et al. Dapagliflozin, a novel SGLT2 inhibitor, induces dose-dependent glucosuria in healthy subjects. Clin Pharmacol Ther. 2009;85(5):520-526.

12. Heise T, Seewaldt-Becker E, Macha S, et al. Safety, tolerability, pharmacokinetics and pharmacodynamics following 4 weeks' treatment with empagliflozin once daily in patients with type 2 diabetes. Diabetes Obes Metab. 2013;15(7):613-621. 
13. Sha S, Devineni D, Ghosh A, et al. Canagliflozin, a novel inhibitor of sodium glucose co-transporter 2, dose dependently reduces calculated renal threshold for glucose excretion and increases urinary glucose excretion in healthy subjects. Diabetes Obes Metab. 2011;13(7):669-672.

14. Washburn WN, Poucher SM. Differentiating sodium-glucose cotransporter-2 inhibitors in development for the treatment of type 2 diabetes mellitus. Expert Opin Investig Drugs. 2013;22(4):463-486.

15. Abdul-Ghani MA, Norton L, DeFronzo RA. Renal sodium-glucose cotransporter inhibition in the management of type 2 diabetes mellitus. Am J Physiol Renal Physiol. 2015;309(11):F889-F900.

16. Thomson SC, Rieg T, Miracle C, et al. Acute and chronic effects of SGLT2 blockade on glomerular and tubular function in the early diabetic rat. Am J Physiol Regul Integr Comp Physiol. 2012;302(1):R75-R83.

17. Merovci A, Solis-Herrera C, Daniele G, et al. Dapagliflozin improves muscle insulin sensitivity but enhances endogenous glucose production. J Clin Invest. 2014;124(2):509-514.

18. Zinman B, Wanner C, Lachin JM, et al. Empagliflozin, cardiovascular outcomes, and mortality in type 2 diabetes. $N$ Engl J Med. 2015; 373(22):2117-2128.

19. Yusuf S, Hawken S, Ounpuu S, et al. Effect of potentially modifiable risk factors associated with myocardial infarction in 52 countries (the INTERHEART study): case-control study. Lancet. 2004;364(9438):937-952.

20. Tikkanen I, Chilton R, Johansen OE. Potential role of sodium glucose cotransporter 2 inhibitors in the treatment of hypertension. Curr Opin Nephrol Hypertens. 2016;25(2):81-86.

21. Liakos A, Karagiannis T, Athanasiadou E, et al. Efficacy and safety of empagliflozin for type 2 diabetes: a systematic review and metaanalysis. Diabetes Obes Metab. 2014;16(10):984-993.

22. Virmani R, Burke AP, Farb A, Kolodgie FD. Pathology of the vulnerable plaque. J Am Coll Cardiol. 2006;47(8 suppl):C13-C18.

23. Ojima A, Matsui T, Nishino Y, Nakamura N, Yamagishi S. Empagliflozin, an inhibitor of sodium-glucose cotransporter 2 exerts anti-inflammatory and antifibrotic effects on experimental diabetic nephropathy partly by suppressing AGEs-receptor axis. Horm Metab Res. 2015;47(9):686-692.

24. Patil VC, Patil HC, Shah KB, Vasani JD, Shetty P. Diastolic dysfunction in asymptomatic type 2 diabetes mellitus with normal systolic function. J Cardiovasc Dis Res. 2011;2(4):213-222.

25. Redfield MM, Jacobsen SJ, Burnett JC Jr, Mahoney DW, Bailey KR, Rodeheffer RJ. Burden of systolic and diastolic ventricular dysfunction in the community: appreciating the scope of the heart failure epidemic. JAMA. 2003;289(2):194-202.

26. Bella JN, Palmieri V, Roman MJ, et al. Mitral ratio of peak early to late diastolic filling velocity as a predictor of mortality in middle-aged and elderly adults: the Strong Heart Study. Circulation. 2002;105(16): 1928-1933.

27. Chilton R, Tikkanen I, Cannon CP, et al. Effects of empagliflozin on blood pressure and markers of arterial stiffness and vascular resistance in patients with type 2 diabetes. Diabetes Obes Metab. 2015;17(12): 1180-1193.

28. Kodama S, Horikawa C, Fujihara K, et al. Meta-analysis of the quantitative relation between pulse pressure and mean arterial pressure and cardiovascular risk in patients with diabetes mellitus. Am J Cardiol. 2014;113(6): 1058-1065.

29. Vlachopoulos C, Aznaouridis K, Stefanadis C. Prediction of cardiovascular events and all-cause mortality with arterial stiffness: a systematic review and meta-analysis. J Am Coll Cardiol. 2010;55(13): 1318-1327.

30. Franklin SS, Larson MG, Khan SA, et al. Does the relation of blood pressure to coronary heart disease risk change with aging? The Framingham Heart Study. Circulation. 2001;103(9):1245-1249.

31. Mottram PM, Haluska BA, Leano R, Carlier S, Case C, Marwick TH. Relation of arterial stiffness to diastolic dysfunction in hypertensive heart disease. Heart. 2005;91(12):1551-1556.

32. Lubrano V, Balzan S. Roles of LOX-1 in microvascular dysfunction. Microvasc Res. 2016;105:132-140.
33. Bakris GL, Bank AJ, Kass DA, Neutel JM, Preston RA, Oparil S. Advanced glycation end-product cross-link breakers. A novel approach to cardiovascular pathologies related to the aging process. Am J Hypertens. 2004;17(12 pt 2):23s-30s.

34. Neeland IJ, McGuire DK, Chilton R, et al. Empagliflozin reduces body weight and indices of adipose distribution in patients with type 2 diabetes mellitus. Diab Vasc Dis Res. 2016;13(2):119-126.

35. Plosker GL. Canagliflozin: a review of its use in patients with type 2 diabetes mellitus. Drugs. 2014;74(7):807-824.

36. Cefalu WT, Leiter LA, Yoon KH, et al. Efficacy and safety of canagliflozin versus glimepiride in patients with type 2 diabetes inadequately controlled with metformin (CANTATA-SU): 52 week results from a randomised, double-blind, phase 3 non-inferiority trial. Lancet. 2013;382(9896):941-950.

37. Plosker GL. Dapagliflozin: a review of its use in patients with type 2 diabetes. Drugs. 2014;74(18):2191-2209.

38. Baker WL, Smyth LR, Riche DM, Bourret EM, Chamberlin KW, White WB. Effects of sodium-glucose co-transporter 2 inhibitors on blood pressure: a systematic review and meta-analysis. $J$ Am Soc Hypertens. 2014;8(4):262-275.e269.

39. Scirica BM, Bhatt DL, Braunwald E, et al. Saxagliptin and cardiovascular outcomes in patients with type 2 diabetes mellitus. N Engl J Med. 2013;369(14):1317-1326

40. Green JB, Bethel MA, Armstrong PW, et al. Effect of sitagliptin on cardiovascular outcomes in type 2 diabetes. N Engl J Med. 2015;373(3): 232-242.

41. Spinar J, Spinarova L, Vitovec J. [The TECOS, EXAMINE and SAVOR studies - how do they differ and what are their outcomes?]. Vnitr Lek. 2015;61(11):976-983. In Czech.

42. Mozaffarian D, Benjamin EJ, Go AS, et al. Executive summary: heart disease and stroke statistics-2016 update: a report from the American Heart Association. Circulation. 2016;133(4):447-454.

43. Tracqui P, Broisat A, Toczek J, Mesnier N, Ohayon J, Riou L. Mapping elasticity moduli of atherosclerotic plaque in situ via atomic force microscopy. J Struct Biol. 2011;174(1):115-123.

44. Pedrigi RM, de Silva R, Bovens SM, Mehta VV, Petretto E, Krams R. Thin-cap fibroatheroma rupture is associated with a fine interplay of shear and wall stress. Arterioscler Thromb Vasc Biol. 2014;34(10): 2224-2231.

45. Cusi K, Consoli A, DeFronzo RA. Metabolic effects of metformin on glucose and lactate metabolism in noninsulin-dependent diabetes mellitus. J Clin Endocrinol Metab. 1996;81(11):4059-4067.

46. Cherney DZ, Perkins BA, Soleymanlou N, et al. Renal hemodynamic effect of sodium-glucose cotransporter 2 inhibition in patients with type 1 diabetes mellitus. Circulation. 2014;129(5):587-597.

47. Heart Outcomes Prevention Evaluation (HOPE) Study Investigators. Effects of ramipril on cardiovascular and microvascular outcomes in people with diabetes mellitus: results of the HOPE study and MICROHOPE substudy. Heart Outcomes Prevention Evaluation Study Investigators. Lancet. 2000;355(9200):253-259.

48. White WB, Cannon CP, Heller SR, et al. Alogliptin after acute coronary syndrome in patients with type 2 diabetes. $N$ Engl $J$ Med. 2013;369(14):1327-1335

49. Okada M, Matsumori A, Ono K, et al. Cyclic stretch upregulates production of interleukin- 8 and monocyte chemotactic and activating factor/monocyte chemoattractant protein-1 in human endothelial cells. Arterioscler Thromb Vasc Biol. 1998;18(6):894-901.

50. UK Prospective Diabetes Study Group. Tight Blood Pressure Control and Risk of Macrovascular and Microvascular Complications in Type 2 Diabetes: UKPDS 38. BMJ. 1998;317(7160):703-713.

51. The ADVANCE Collaborative Group. Intensive blood glucose control and vascular outcomes in patients with type 2 diabetes. $N$ Engl $J$ Med. 2008;358:2560-2572. 
Therapeutics and Clinical Risk Management

Dovepress

\section{Publish your work in this journal}

Therapeutics and Clinical Risk Management is an international, peerreviewed journal of clinical therapeutics and risk management, focusing on concise rapid reporting of clinical studies in all therapeutic areas outcomes, safety, and programs for the effective, safe, and sustained use of medicines. This journal is indexed on PubMed Central, CAS,

Ease, Scopus and the Elsevier Bibliographic databases. The manuscript management system is completely online and includes a very quick and fair peer-review system, which is all easy to use. Visit http://www.dovepress.com/testimonials.php to read real quotes from published authors.

Submit your manuscript here: http://www.dovepress.com/therapeutics-and-clinical-risk-management-journal 